\title{
US 'hands-off' forest policy challenged by Yellowstone fire
}

\section{Boston}

THE worst forest fires to strike the United States for many decades continued to rage last week at Yellowstone National Park in Wyoming and in neighbouring states, and have now ignited a vigorous debate about US policy for monitoring and managing forest fires in wilderness areas.

Including fires in Alaska, a total area of more than 4 million acres of forest has been burnt to the ground this year. At least 40 per cent of Yellowstone's 2.2 million acres has been razed. Since the early 1970 s, the official US policy has been to let forest fires burn at national parks and
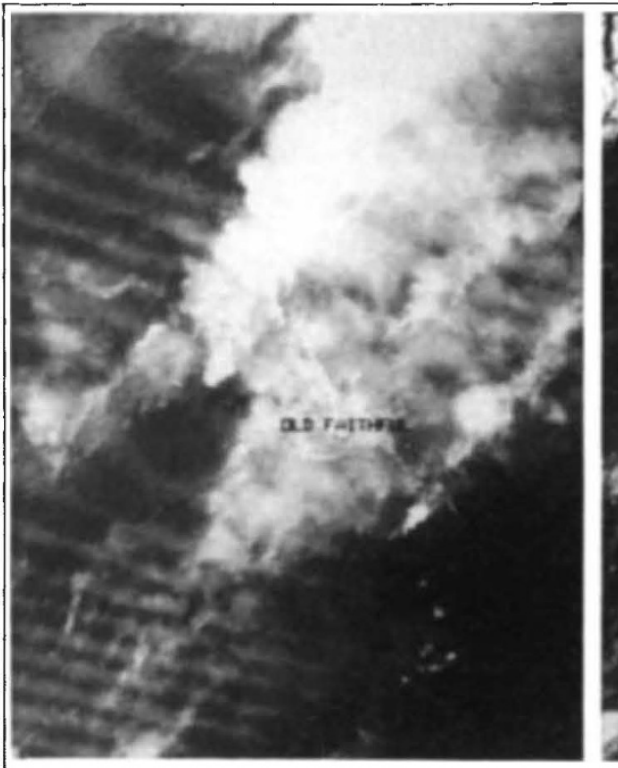

a major policy shift by the park service, is a readjustment of the balance on a difficult topic; congressional hearing, later in the year will debate it more fully.

At issue are fundamental questions about the nature and purpose of parklands in the United States. Most conservationists contend that the vast majority of these public areas are not frequently visited and should be kept in as natural a state as possible. Forest fires, they say, deplete the natural accumulation of burnable "fuel" made up of dry dead growth, and put fresh nutrients into the soil.

But others suggest that the heavy

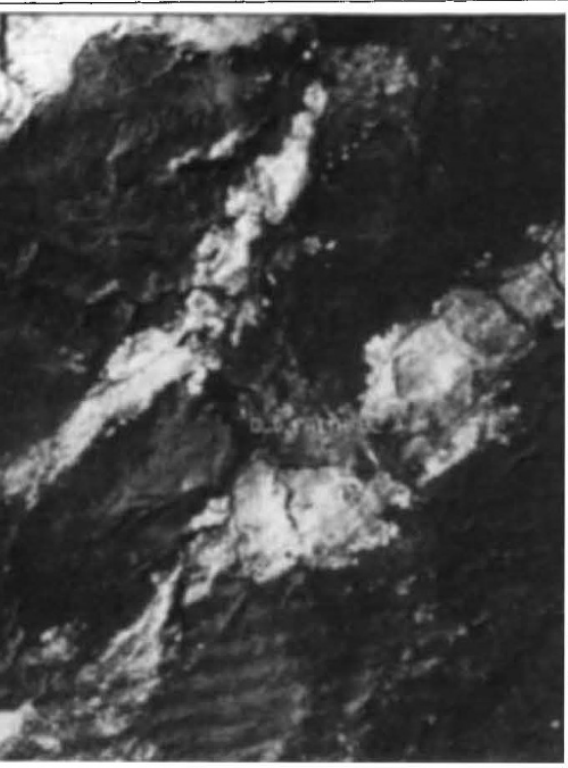

Images of the fire crossing the Old Faithful community in the visible (left) and thermal infrared wavelengths. The burning area is seen as a light region in the thermal image. Photos taken on 9 September from a NASA ER-2 aircraft at 65,000 feet.

forests unless they clearly threaten human life or private property. Ecologists and conservationists have generally supported this "let-burn" policy, often called the "natural fire policy", on the grounds that fires are part of the natural process for rejuvenating forests. For a century before 1970 , the United States had attempted to suppress fires in wilderness areas, which may have ultimately caused more destruction by allowing dry fallen wood to accumulate in dangerous amounts on the forest floors.

Under political pressure from the Wyoming delegation, Secretary of the Interior Donald P. Hodel announced last week that the National Park Service will now deviate slightly from its hands-off fire policy by planting new forests and vegetation in some park areas destroyed by this year's fires and by feeding some wildlife, such as elk and bison, to stop them migrating onto nearby private property.

Hodel's statement, while not indicating recreational demands on key portions of the parks create a need for tighter management and control of the land. This group adds that the finite plots designated as wilderness areas should not be seen as self-regulating ecosystems, but need to be maintained to serve their function to society for recreation.

In practice, much of the debate may be inconclusive because of the semi-arid nature of many of the national forests in the United States, and the frequent occurrence of dry lightning storms. By almost all accounts, the accumulating woody fuels cannot be borne by the forest indefinitely. Once full-scale forest fires begin, it is unclear whether efforts at fire suppresion are at all effective.

As present, some 30,000 fire fighters, including US Army and Marine troops, have been at work fighting the blazes. The effort has cost at least $\$ 300$ million so far and has claimed the lives of at least seven fire fighters. Recently the effort has been

\section{Defence money for} superconductors

\section{Washington}

IN a programme aimed specifically at fostering the technological development of high-temperature superconductors, the Defense Advanced Research Projects Agency (DARPA) is planning to distribute about $\$ 30$ million to nearly 40 industrial and academic research groups.

Although devices of some military consequence are the ultimate goal, DARPA's initial purpose is to improve the physical properties of the superconducting ceramics and to distinguish feasible from unrealistic applications.

Robert Shelton, a physicist at the University of California at Davis, praised the DARPA programme for its effort to coordinate the research talents of many different organizations, and for selecting a number of rather low-key but achievable technological goals, such as levitating bearings, magnetic sensors and superconducting coatings for radio-frequency cavities.

Shelton is associated with Ceracon Inc., of Sacramento, California, which has been given $\$ 500,000$ to adapt its highpressure ceramic fabrication methods to the creation of dense superconductors with higher critical currents than the usual laboratory product.

Recipients of DARPA money met in Washington last week to compare notes and to give DARPA a chance to assess progress and suggest new directions and collaborations. According to Shelton, companies or universities with specific areas of expertise that fit in with DARPA's aims stand to profit from the programme, but those that turned up with vague ideas and some hope of a few hundred thousand dollars of federal money went away disappointed.

David Lindley

joined by a specially trained fire fighting contingent from Canada. Infrared scanners from NASA, flying in planes as high as 70,000 feet above the fires, have mapped a thermal picture of the fires to aid those trying to contain them.

Despite these efforts, most acknowledge that the campaigns have been largely futile. Some of the most serious property damage may have even been caused by fires started intentionally in an effort to create fire-breaks.

When the dry conditions and high winds favour a spreading forest fire, there apparently is not much that can be done. As Steven Whitney, director of the National Parks Program for the Wilderness Society, said, "you could have had wall-to-wall fire hydrants at Yellowstone and it probably wouldn't have made any difference". 